\title{
Thermal Performance Testing of a Ceramic Solar Collecting System
}

\author{
Chongjie Wang1, a, Ding Ding ${ }^{1, b}$, Xiaohan $\mathrm{Xu}^{1, \mathrm{c}}$ \\ ${ }^{1}$ School of Architecture and Urban Planning, Shandong Jianzhu University, No. 1000 Fengming \\ Road, Jinan 250101, China \\ awcj@sdjzu.edu.cn, bding7777ding@foxmail.com, c2293694831@qq.com
}

Keywords: Ceramic collector; solar energy; rural residence; winter heating

Abstract. The low-cost and long-life ceramic solar collector provides a new train of thought to solve the heating problem in Chinese rural areas. Through testing, the average daily useful heat gain of the ceramic solar system is $7.08 \mathrm{MJ} / \mathrm{m}^{2}$, and the average collecting efficiency is $41.63 \%$.

\section{Introduction}

During 16 to 21 December, 2016, the area of fog and haze in China came up to $142 \times 104 \mathrm{~km}^{2}$. This phenomenon is strongly associated with the small coal stoves heating method widely used in China's vast rural area. However, on the one hand, in the middle part of China, there are still tens of millions of rural residences have the need of heating. As living standards improving, the environmental problem will be even more serious. On the other hand, it is impracticable to meet this heating demand only by using electricity or natural gas, which is a common way in developed countries, in China's impoverished rural area. Then, as the results of the energy-saving and emission-reduction policy, the application quantity of solar heating technologies in buildings has increased obviously, and the requirement for building integrated solar energy has been higher and higher. However, glass vacuum tube collector and metal flat plate collector, which are commonly adopted around the China, have the prominent problems of high cost, low efficiency, and unreasonable installation. Most importantly, these two types of collector cannot achieve the same service life as long as building.

A new kind of ceramic solar collector (Fig. 1), which can be used for more than 50 years, provides a novel train of thought to solar building application in rural residences. The main body of the ceramic solar collector is made from normal white ceramic. V-Ti black ceramic coating is sprayed on its exterior surface to absorb solar energy. And around the cavity inside the plate, there's a layer of glaze to prevent the retention of heating medium. The whole plate is fired at a temperature above $1200{ }^{\circ} \mathrm{C}$, which ensures the age resistance and performance stability of the collector ${ }^{[1]}$.

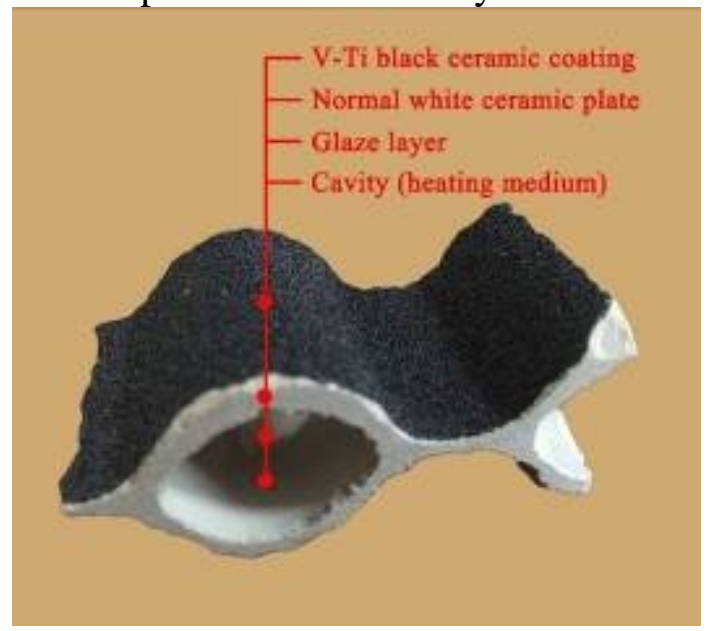

Fig. 1. Section of a ceramic solar collector.

So far, there is no reference aiming at the applicability of ceramic solar collecting system utilized on rural residences. After investing the existing ceramic solar projects in China, the authors find that these projects are located between $23 \mathrm{~N}$ to $44 \mathrm{~N}$, and are primarily located in Cold Zone ${ }^{\text {[2] }}$ (Fig. 2). Firstly, 3/4 of them are rural projects, and only 1/4 of them are utilized in cities. Secondly, in the aspect of building type, nearly half of these projects are dwelling constructions. There are still some 
education, agriculture, industry, restaurant, and sports buildings. In regard to building height, only two of the systems are installed on the exterior walls of high-rise buildings, and the others are all utilized on low-rise buildings, especially on the roofs of rural residences. Thirdly, the collecting areas of existing projects are normally not very large (usually $10 \sim 100 \mathrm{~m}^{2}$ ). There are still lots of the systems less than $10 \mathrm{~m}^{2}$, which can only provide domestic hot water rather than winter heating for buildings.

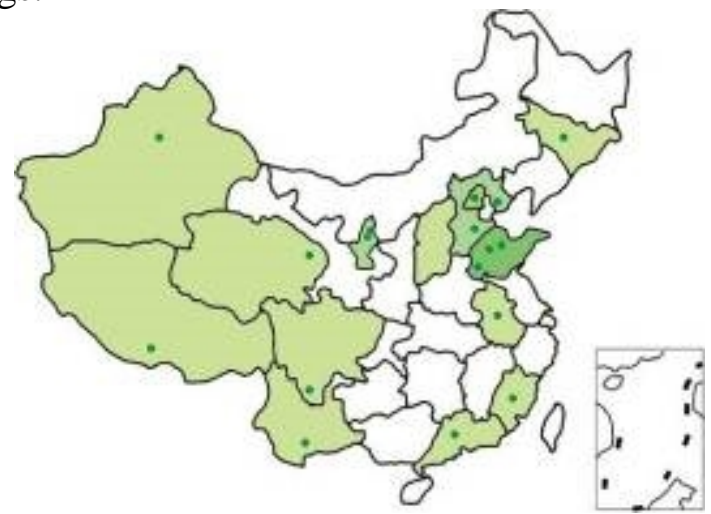

Fig. 2. Location of existing projects in China

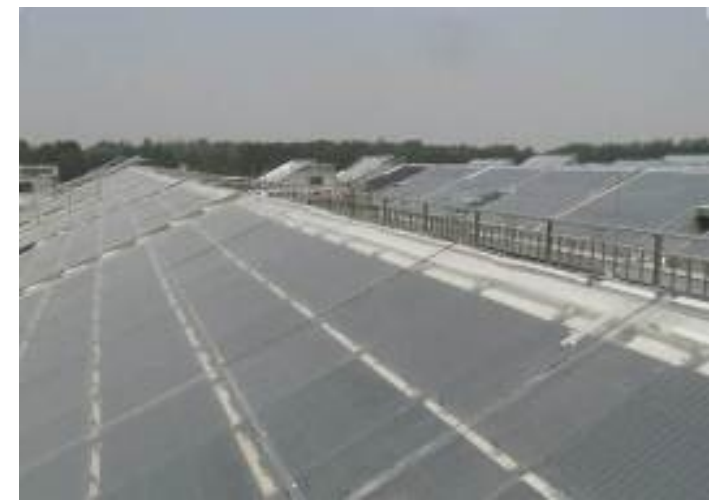

Fig. 3. Image of Wupingfang Village

\section{Project overview.}

In order to know the thermal performance of ceramic solar collecting system, the authors conducted a project testing in Wupingfang Village, Heze, Shandong Province (Fig. 3). According to relevant standard, this experiment utilized a TRM-2A type testing system for solar water heating performance. The testing time was every day's 9 am to 16 pm in January, the coldest month of Shandong. The interval of data acquisition was 1 minute. The testing parameters were the amount of solar radiation, and the temperature of water, etc.

This direct-type system $(35.27 \mathrm{~N}, 116.27 \mathrm{E})$ is installed on the southern roof of a single-sloped rural residence. Its primary aim is to provide heating source in winter, as well as domestic hot water in other seasons. The residential building has 3 storeys. The ground floor and the first floor are main living spaces, namely heating spaces, and the second floor is storage spaces. Fig. 4 shows the plan of the living spaces of this building. The width of it is $7.8 \mathrm{~m}$, the depth is $9.9 \mathrm{~m}$, and the area is $163.05 \mathrm{~m}^{2}$.
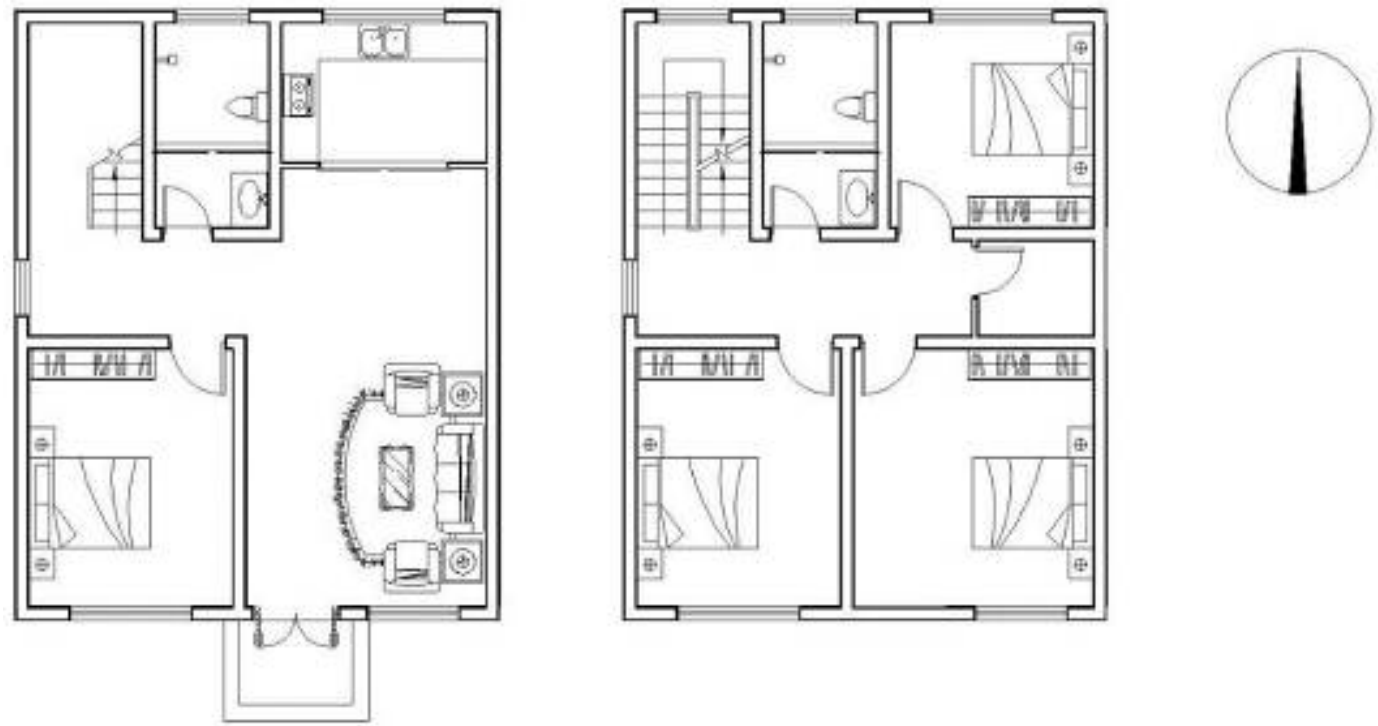

Fig. 4. Plan of the ground floor and the first floor

The system is composed of 102 ceramic flat plates $(720 \mathrm{~mm} \times 720 \mathrm{~mm}$, Fig. 5) mounted on the roof, a heat storage tank (1.5t) located in the kitchen, a number of radiators installed in the living room and bedrooms, and accessories such as pipes, etc. Fig.6 indicates the structure of the rooftop collectors. The orientation of the devices is south, the inclination is approximately $20^{\circ}$, and the contour aperture area $\left(A_{\varepsilon}\right)$ is $52.88 \mathrm{~m}^{2}$. 


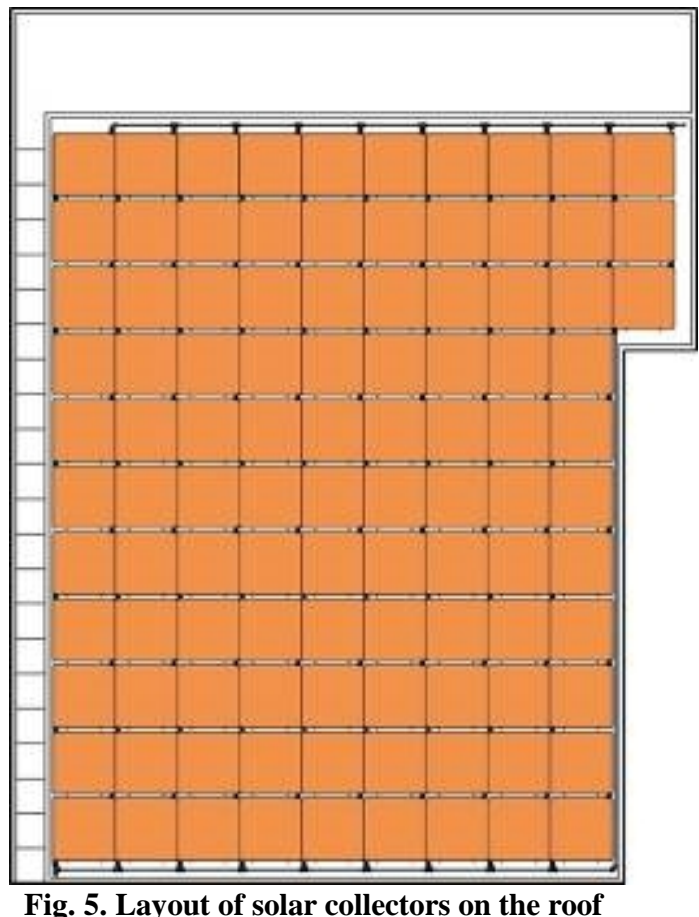

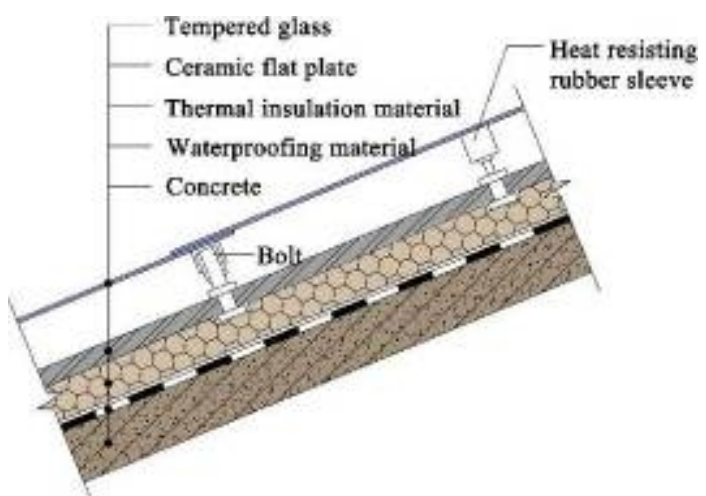

Fig. 6. Detail drawing of the ceramic solar roof

\section{Thermal performance calculation}

The system heat gain $\left(Q_{\xi}\right)$ can be expressed as:

$$
Q_{s}=\beta_{w} V_{s} c_{p w}\left(t_{a}-t_{b}\right) \times 10^{-6}
$$

in which $p_{w}$ is the density of water $\left(1.0 \times 10^{3} \mathrm{~kg} / \mathrm{m}^{3}\right), V_{s}$ is the volume of the heat storage tank $\left(\mathrm{m}^{3}\right)$, $c_{p w}$ is the specific heat ratio of water $\left(4.2 \times 10^{3} \mathrm{~J} / \mathrm{kgK}\right)$, and $t_{\varepsilon}$ and $t_{z}$ are the temperatures in the tank when the testing ends and begins $\left({ }^{\circ} \mathrm{C}\right)$ respectively. In order to make the testing results more comparable, the daily useful heat gain of unit $A_{\varepsilon}$ when the solar radiation is $17 \mathrm{MJ} / \mathrm{m}^{2}(q)$ can be defined as:

$$
q=\frac{17 Q_{s}}{H A_{0}}
$$

in which $H$ is the daily cumulative solar radiation $\left(\mathrm{MJ} / \mathrm{m}^{2}\right)$. Then the average collecting efficiency of the system $(\eta)$ can be calculated as

$$
\eta=\frac{Q_{s}}{H A_{c}}
$$

And the transient collecting efficiency of the system based on $A_{c}\left(\eta_{c}\right)$ can be expressed as

$$
\eta_{o}=\frac{m\left(T_{o}-T_{i}\right) c_{f}}{A_{c} G}
$$

in which $m$ is the flow rate of the media $(\mathrm{kg} / \mathrm{s}), T_{o}$ and $T_{i}$ are the temperatures of the media at the outlet and the inlet $\left({ }^{\circ} \mathrm{C}\right)$ respectively, $c_{j}$ is the specific heat ratio of the media based on the average media temperature $(\mathrm{J} / \mathrm{kgK})$, and $G$ is the solar radiation intensity $\left(\mathrm{W} / \mathrm{m}^{2}\right)$.

\section{Testing results}

The paper analyzes the data of 10 January, when the climate condition was relatively steady. Fig.7 shows the relationship between $T_{0}$ and $T_{i}$ by minute. The lowest $T_{i}$ of the day was $3.9^{\circ} \mathrm{C}$ at about 8 am, the highest one was $15.5^{\circ} \mathrm{C}$ at about $1 \mathrm{pm}$, and the average value was $11.9^{\circ} \mathrm{C}$. Generally speaking, $T_{\circ}$ went up with time. The lowest $T_{*}$ was $37.1{ }^{\circ} \mathrm{C}$, the highest one was $53.3{ }^{\circ} \mathrm{C}$, and the average value was $43.8^{\circ} \mathrm{C}$. The average rise in temperature was $31.9^{\circ} \mathrm{C}$. Fig. 8 expressed the relationship between $G$ and $q_{s}$ by minute. The value of $G$ was 54 to $691 \mathrm{~W} / \mathrm{m}^{2}$ during 8 am to $4 \mathrm{pm}$. The peak value appeared at about $11 \mathrm{am}$, and the valley value showed up at about $4 \mathrm{pm} . q_{5}$ of the whole day was steady at approximately $200 \mathrm{~W} / \mathrm{m}^{2}$, and had the tendency to increase after noon. 


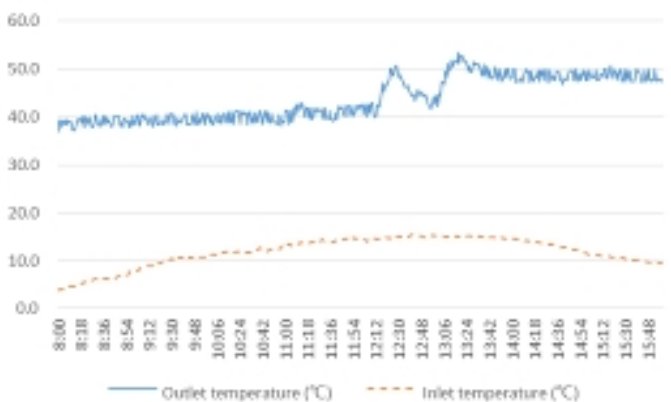

Fig. 7. Temperature at the inlet and outlet of the collectors

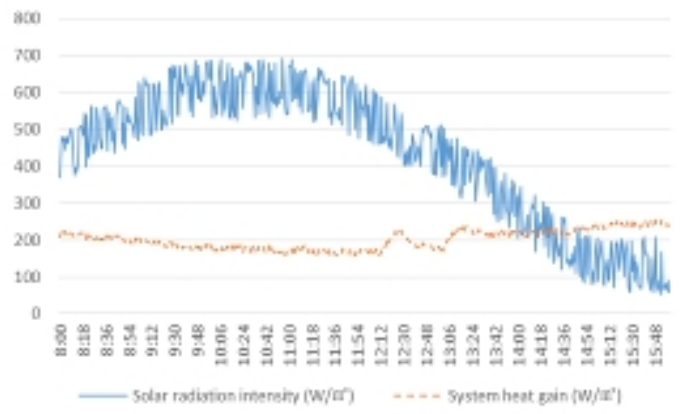

Fig. 8. Solar radiation intensity and system heat gain

The parameters for the calculation of $q$ and $\eta$ are shown in Table 1. As can be observed, the $q$ value was $7.08 \mathrm{MJ} / \mathrm{m}^{2}$, higher than the requirement of $7.0 \mathrm{MJ} / \mathrm{m}^{2}$ ruled by the Chinese standard Specification of domestic solar water heating systems. Accordingly, the $\eta$ value during the experiment was $41.63 \%$.

Table 1 Parameters for daily useful heat gain and collecting efficiency

\begin{tabular}{|c|c|c|c|c|c|}
\hline$t_{b}$ & $\tau_{\boldsymbol{z}}$ & $\boldsymbol{H}$ & $Q_{s}$ & $\boldsymbol{q}$ & $\eta$ \\
\hline 4.0 & 47.6 & 12.477 & 274.68 & 7.08 & 41.63 \\
\hline
\end{tabular}

Apart from verifying the system's thermal performance according to relevant standards, this experiment also tested the relationship between $\eta_{\kappa}$ and $G$. Fig. 9 shows the inversed connection when flow rate was $0.02 \mathrm{~kg} / \mathrm{s}$.

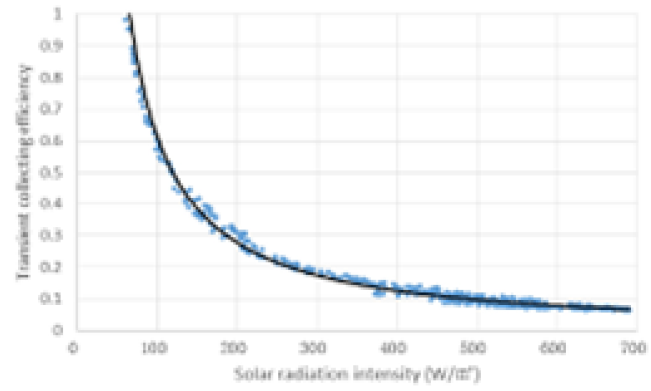

Fig. 9. Transient collecting efficiency and solar radiation intensity

\section{Conclusions}

The low-cost and long-life ceramic solar collector provided a new train of thought to solve the heating problem in Chinese rural areas. In order to know the thermal performance of ceramic solar collecting system, this study conducted a project testing. Generally speaking, the outlet temperature went up with time. The average rise in temperature was $31.9^{\circ} \mathrm{C}$, the average daily useful heat gain of the project is $7.08 \mathrm{MJ} / \mathrm{m}^{2}$, and the average collecting efficiency is $41.63 \%$. The transient collecting efficiency of the system was inversely proportional to solar radiation intensity.

\section{Acknowledgement}

This work was supported by Chinese National Natural Science Foundation [51778350].

\section{References}

[1] Y. Yang, Q. Wang, D. Xiu, Z. Zhao, Q. Sun, A building integrated solar collector: All-ceramic solar collector, Energy Build. 62 (2013) 15-17. doi:10.1016/j.enbuild.2013.03.002.

[2] I. and Q. General Administration of Quality Supervision, Test methods for thermal performance of domestic solar water heating systems, 2002nd ed., China Standards Press, Beijing, 2002. (In Chinese) 